\title{
Solvability of fractional $p$-Laplacian boundary value problems with controlled parameters
}

Tengfei Shen, Wenbin Liu*

School of Mathematics, China University of Mining and Technology, Xuzhou 221116, P. R. China.

Communicated by K. Q. Lan

\begin{abstract}
This paper aims to investigate existence of solutions of several boundary value problems for fractional one-dimensional p-Laplacian equation under controlled parameters. By employing fixed point theory and critical point theory, some new results are obtained, which enrich and generalize the previous results. (C)2017 All rights reserved.
\end{abstract}

Keywords: Fractional ordinary differential equation, boundary value problem, p-Laplacian operator, existence. 2010 MSC: 26A33, 34B15, 34G20.

\section{Introduction}

In recent years, fractional differential equations are viewed as useful mathematical models and applied in many research fields (see [20, 24, 26, 30, 35]). For example, Leszczynski and Blaszczyk [24] made use of a class of fractional differential equation to present the height of granular material falling over time in a silo:

$$
{ }^{\mathrm{C}} \mathrm{D}_{\mathrm{T}^{-}}^{\alpha} \mathrm{D}_{\mathrm{a}^{+}}^{\alpha} \mathrm{h}^{*}(\mathrm{t})+\beta \mathrm{h}^{*}(\mathrm{t})=0, \quad \mathrm{t} \in[0, \mathrm{~T}],
$$

where $\alpha \in(0,1),{ }^{C} D_{T^{-}}^{\alpha}$ and $D_{a^{+}}^{\alpha}$ stand for right Caputo fractional derivatives and left Riemann-Liouville fractional derivatives respectively, $h^{*}(t)=h_{b e d}-h(t), h(t)$ means dropping height for silo emptying, $h_{\text {bed }}$ is the initial bed height. Szymanek [31] used the following fractional differential equation to describe the temperature profiles in a granular layer:

$$
{ }^{\mathrm{C}} \mathrm{D}_{\mathrm{b}^{-}}^{\alpha{ }^{C}} \mathrm{D}_{\mathrm{a}^{+}}^{\alpha} \mathrm{T}(\mathrm{x})+\lambda \mathrm{T}(\mathrm{x})=0, \quad x \in[\mathrm{a}, \mathrm{b}],
$$

which is associated with the following boundary conditions

$$
\mathrm{T}(\mathrm{a})=\mathrm{T}_{0}, \quad \mathrm{~T}(\mathrm{~b})=\mathrm{T}_{1}, \quad \mathrm{~T}^{\prime}(\mathrm{a})=\mathrm{T}_{2}, \quad \mathrm{~T}^{\prime}(\mathrm{b})=\mathrm{T}_{3} .
$$

Here, $\alpha \in(1,2),{ }^{C} D_{a^{+}}^{\alpha}$ and ${ }^{C} D_{b^{-}}^{\alpha}$ represent left and right Caputo fractional derivatives, respectively.

\footnotetext{
*Corresponding author

Email addresses: stf cool@126.com (Tengfei Shen), cumt_equations@126.com (Wenbin Liu)
} 
Thus, the study of fractional boundary value problems have attracted many scholars' attention. And some classical nonlinear functional methods has been applied to investigate the existence of solutions of fractional boundary value problems such as fixed point theorems (see $[1,13,23]$ ), coincidence degree theory (see $[16,21])$, etc. Recently, for boundary value problems involving ${ }_{t} D_{T 0}^{\alpha} D_{t}^{\alpha}$ operator, Jiao and Zhou $[17,18]$ have shown that critical point theory can be used to present existence of solutions for this type operator with Dirichlet boundary conditions. For example, in [18], they considered the existence of solutions of following system:

$$
\left\{\begin{array}{l}
{ }_{t} D_{T}^{\alpha}\left({ }_{0} D_{t}^{\alpha} u(t)\right)=\nabla F(t, u(t)), \text { a.e. } t \in[0, T] \\
\mathfrak{u}(0)=\mathfrak{u}(T)=0
\end{array}\right.
$$

where ${ }_{0} D_{t}^{\alpha}$ and ${ }_{t} D_{T}^{\alpha}$ left and right are Riemann-Liouville fractional derivatives, $\alpha \in(0,1]$. By employing mountain pass theorem and the classical Ambrosetti-Rabinowitz condition, the existence of weak nontrivial solutions was obtained for $\alpha \in\left(\frac{1}{2}, 1\right]$. After that, Torres [38] took further discussion of this type problem in scalar case by using mountain pass theorem. Bonanno et al. [7] considered this type problem with impulsive effects and proved existence of three solutions by using a critical point theorem given in [6]. Furthermore, some scholars devoted to developing and perfecting fractional Soblev space (see $[5,15,19])$.

On the other hand, initial value problems of fractional functional differential equations have also attracted many scholars' attention (see [2, 4, 22, 29, 39]). For example, in [2], Agarwal et al. considered the following initial value problem for a fractional neutral functional differential equation as follows:

$$
\left\{\begin{array}{l}
{ }^{C} D^{\alpha}\left(u(t)-g\left(t, u_{t}\right)\right)=f\left(t, u_{t}\right), \quad t \in\left(t_{0},+\infty\right), t_{0} \geqslant 0 \\
u_{t_{0}}=\varphi
\end{array}\right.
$$

where ${ }^{C} D^{\alpha}$ is Caputo's fractional derivative of order $0<\alpha<1, g, f:\left[t_{0}, \infty\right] \times C\left([-r, 0], R^{n}\right) \rightarrow R^{n}$, $u_{t}(\theta)=u(t+\theta), \theta \in[-r, 0], \varphi(t) \in C\left([-r, 0], R^{n}\right)$. Moreover, Bai [3] studied the existence of positive solutions for a class of fractional functional boundary value problems by employing Guo-Krasnoselskii fixed point theorem.

In fact, boundary value problems with p-Laplacian operator are classical problems in integer differential equations (see $[6,8,11,25,27,36,37]$ and references therein). Naturally, fractional boundary value problems with $p$-Laplacian operator have received much attention (see $[10,33]$ and references therein). Note that in [10], Chen and Liu extended (1.1) to p-Laplacian case and obtained some existence results by critical point theory.

Motivated by the works mentioned above, on one hand, we discuss existence of solutions of fractional p-Laplacian Dirichlet boundary value problem with the general nonlinearity and two controlled parameters by critical point theory:

$$
\left\{\begin{array}{l}
{ }_{t} D_{T}^{\alpha} \phi_{p}\left({ }_{0} D_{t}^{\alpha} u(t)\right)+b(t) \phi_{p}(u(t))=\lambda f(t, u(t))+\mu g(t, u(t)), \quad \text { a.e. } t \in(0, T) \\
u(0)=u(T)=0
\end{array}\right.
$$

where $\alpha \in(0,1], b(t) \in L^{\infty}[0, T], 1<p<\infty, \phi_{p}(s)=|s|^{p-2} s(s \neq 0), \phi_{p}(0)=0, \phi_{p}^{-1}=\phi_{q}, 1 / p+1 / q=1$; $\mathrm{f}, \mathrm{g}:[0, \mathrm{~T}] \times \mathbb{R} \rightarrow \mathbb{R}$ are continuous; $\lambda>0, \mu \geqslant 0$ are constants; ${ }_{0} \mathrm{D}_{\mathrm{t}}^{\alpha}$ and ${ }_{\mathrm{t}} \mathrm{D}_{\mathrm{T}}^{\alpha}$ represent left and right Riemann-Liouville fractional derivatives respectively.

By giving the bound of parameters, we can ensure its existence of solutions. Note that if $p=2, \lambda=$ $1, \mu=0,(1.2)$ implies (1.1) in scalar case. Moreover, if $p=2, \alpha=1$, we have

$$
{ }_{t} D_{T}^{\alpha}\left(\left.l_{0} D_{t}^{\alpha} u(t)\right|^{p-2}{ }_{0} D_{t}^{\alpha} u(t)\right)={ }_{t} D_{T}^{\alpha}\left({ }_{0} D_{t}^{\alpha} u(t)\right)=-u^{\prime \prime} .
$$

Thus, our main results enrich and generalize the previous results.

On the other hand, from our view, there are relatively few articles which investigated the existence of positive solutions for boundary value problems of fractional delay differential equations with $p$-Laplacian 
operator. Hence, we consider the existence of positive solutions for boundary value problems of fractional delay differential equations with p-Laplacian operator and a controlled parameter by applying GuoKrasnoselskii fixed point theorem:

$$
\left\{\begin{array}{l}
{ }_{0}^{c} D_{t}^{\beta} \phi_{p}\left({ }_{0}^{c} D_{t}^{\alpha} \mathfrak{u}(t)\right)-\lambda a(t) f(t, u(t-\tau))=0, \quad \text { a.e. } t \in(0, T), \\
u(t)=0, \quad t \in[-\tau, 0], \\
u^{\prime}(T)=u^{\prime \prime}(0)=0, \\
\left.\phi_{p}\left({ }_{0}^{c} D_{t}^{\alpha} \mathfrak{u}(t)\right)\right|_{t=0}=\left.\left(\phi_{p}\left({ }_{0}^{c} D_{t}^{\alpha} \mathfrak{u}(t)\right)\right)^{\prime}\right|_{\mathfrak{t}=T}=\left.\left(\phi_{p}\left({ }_{0}^{c} D_{t}^{\alpha} \mathfrak{u}(t)\right)\right)^{\prime \prime}\right|_{t=0}=0,
\end{array}\right.
$$

where ${ }_{0}^{c} D_{t}^{\alpha}$ represents the left Caputo fractional derivative; $2<\alpha, \beta \leqslant 3,0<\tau<\mathrm{T} ; \lambda>0$ is a constant; $f:[0, T] \times[0, \infty) \rightarrow[0, \infty)$ is continuous; $a:[0, T] \rightarrow[0, \infty)$ is continuous and $a(t) \not \equiv$.

\section{Preliminaries}

To begin with, we introduce the basic knowledge concerning with fractional integral and derivative, fractional Sobolev space and variational structure.

Definition $2.1([20,30])$. Let $f$ be a function defined on $[a, b]$.

(i) The left and right Riemann-Liouville fractional integrals of order $\alpha>0$ for a function $f$ are defined by

$$
\begin{array}{ll}
{ }_{a} I_{t}^{\alpha} f(t)=\frac{1}{\Gamma(\alpha)} \int_{a}^{t}(t-s)^{\alpha-1} f(s) d s, & t \in[a, b], \\
{ }_{t} I_{b}^{\alpha} f(t)=\frac{1}{\Gamma(\alpha)} \int_{t}^{b}(s-t)^{\alpha-1} f(s) d s, & t \in[a, b],
\end{array}
$$

provided the right-hand sides are pointwise defined on $[a, b]$, where $\Gamma(\alpha)$ is the standard gamma function.

(ii) If $\alpha=n, n \in \mathbb{N}$, they become the usual definitions

$$
\begin{array}{ll}
{ }_{a} I_{t}^{n} f(t)=\frac{1}{\Gamma(n)} \int_{a}^{t}(t-s)^{n-1} f(s) d s, & t \in[a, b], \\
{ }_{t} I_{b}^{n} f(t)=\frac{1}{\Gamma(n)} \int_{t}^{b}(s-t)^{n-1} f(s) d s, & t \in[a, b] .
\end{array}
$$

Definition 2.2 ([20, 30]). Let $\mathrm{f}$ be a function defined on $[\mathrm{a}, \mathrm{b}]$.

(i) The left and right Riemann-Liouville fractional derivatives of order $\alpha$ for function $f$ denoted by ${ }_{a} D_{t}^{\alpha} f(t)$ and ${ }_{t} D_{b}^{\alpha} f(t)$, respectively, are defined by

$$
{ }_{a} D_{t}^{\alpha} f(t)=\frac{d^{n}}{d t^{n}} a I_{t}^{n-\alpha} f(t), \quad{ }_{t} D_{b}^{\alpha} f(t)=(-1)^{n} \frac{d^{n}}{d t^{n}} t I_{b}^{n-\alpha} f(t),
$$

where $t \in[a, b], n-1 \leqslant \alpha<n$ and $n \in \mathbb{N}$.

(ii) If $\alpha=n-1, n \in \mathbb{N}$, they become the usual definitions

$$
{ }_{a} D_{t}^{n-1} f(t)=f^{n-1}(t), \quad{ }_{t} D_{b}^{n-1} f(t)=(-1)^{n} f^{n-1}(t), \quad t \in[a, b] .
$$

Definition $2.3([20,30])$. Let $\alpha \geqslant 0$ and $n \in \mathbb{N}$. 
(i) If $\alpha \in(n-1, n)$ and $f \in A C^{n}([a, b], \mathbb{R})$, then the left and right Caputo fractional derivatives of order $\alpha$ for function $f$ denoted by ${ }_{a}^{c} D_{t}^{\alpha} f(t)$ and ${ }_{t}^{c} D_{b}^{\alpha} f(t)$, respectively, exist almost everywhere on $[a, b]$, ${ }_{a}^{c} D_{t}^{\alpha} f(t)$ and ${ }_{t}^{c} D_{b}^{\alpha} f(t)$ are represented by

$$
{ }_{a}^{c} D_{t}^{\alpha} f(t)={ }_{a} I_{t}^{n-\alpha} \frac{d^{n}}{d t^{n}} f(t), \quad{ }_{t}^{c} D_{b}^{\alpha} f(t)=(-1)^{n}{ }_{t} I_{b}^{n-\alpha} \frac{d^{n}}{d t^{n}} f(t),
$$

where $t \in[a, b]$

(ii) If $\alpha=n-1$ and $f \in A C^{n-1}([a, b], \mathbb{R})$, then ${ }_{a}^{c} D_{t}^{n-1} f(t)$ and ${ }_{t}^{c} D_{b}^{n-1} f(t)$ are represented by

$$
{ }_{a}^{c} D_{t}^{n-1} f(t)=f^{(n-1)}(t), \quad \text { and } \quad{ }_{t}^{c} D_{b}^{n-1} f(t)=(-1)^{(n-1)} f^{(n-1)}(t), \quad t \in[a, b] .
$$

Proposition 2.4 ([20,30]). Let $\mathrm{n} \in \mathbb{N}$ and $\mathrm{n}-1<\alpha<\mathrm{n}$. If $\mathrm{f}$ is a function defined on $[\mathrm{a}, \mathrm{b}]$ for which the Caputo fractional derivatives ${ }_{a}^{c} D_{t}^{\alpha} f(t)$ and ${ }_{t}^{c} D_{b}^{\alpha} f(t)$ of order $\alpha$ exist together with the Riemann-Liouville fractional derivatives ${ }_{a} D_{t}^{\alpha} f(t)$ and ${ }_{t} D_{b}^{\alpha} f(t)$, then

$$
\begin{aligned}
& { }_{a}^{c} D_{t}^{\alpha} f(t)={ }_{a} D_{t}^{\alpha} f(t)-\sum_{j=0}^{n-1} \frac{f^{j}(a)}{\Gamma(j-\alpha+1)}(t-a)^{j-\alpha}, \quad t \in[a, b], \\
& { }_{t}^{c} D_{b}^{\alpha} f(t)={ }_{t} D_{b}^{\alpha} f(t)-\sum_{j=0}^{n-1} \frac{f^{j}(b)}{\Gamma(j-\alpha+1)}(b-t)^{j-\alpha}, \quad t \in[a, b] .
\end{aligned}
$$

Remark 2.5. Clearly, from (2.1) and (2.2), we can obtain ${ }_{0}^{c} D_{t}^{\alpha} u(t)={ }_{0} D_{t}^{\alpha} \mathfrak{u}(t),{ }_{t}^{c} D_{T}^{\alpha} u(t)={ }_{t} D_{T}^{\alpha} u(t), t \in[0, T]$ by $\mathfrak{u}(0)=\mathfrak{u}(\mathrm{T})=0$.

Proposition 2.6 ([20]). We have the following property of fractional integration

$$
\int_{a}^{b}\left[I_{t}^{\alpha} f(t)\right] g(t) d t=\int_{a}^{b}\left[I_{b}^{\alpha} g(t)\right] f(t) d t, \quad \alpha>0,
$$

provided that $f \in \mathrm{L}^{\mathrm{p}}([\mathrm{a}, \mathrm{b}], \mathbb{R}), \mathrm{g} \in \mathrm{L}^{\mathrm{q}}\left([\mathrm{a}, \mathrm{b}], \mathbb{R}^{\mathrm{N}}\right)$ and $\mathrm{p} \geqslant 1, \mathrm{q} \geqslant 1,1 / \mathrm{p}+1 / \mathrm{q} \leqslant 1+\alpha$ or $\mathrm{p} \neq 1, \mathrm{q} \neq 1$, $1 / p+1 / q=1+\alpha$.

Definition 2.7 ([15]). Let $0<\alpha \leqslant 1$ and $u, v \in \mathrm{L}^{1}[0, \mathrm{~T}]$. For any $\varphi \in \mathrm{C}_{0}^{\infty}[0, \mathrm{~T}]$, we have

$$
\int_{0}^{T} v \varphi d t=\int_{0}^{T} u_{t} D_{T}^{\alpha} \varphi d t
$$

so $v$ is said to be $\alpha$-weak fractional derivative for $u$ and there exists left Riemann-Liouville derivative such that $v={ }_{0} \mathrm{D}_{\mathrm{t}}^{\alpha} \mathrm{u}$.

In fact, by Proposition 2.6, we have

$$
\begin{aligned}
\int_{0}^{T} \varphi_{0} \mathrm{D}_{\mathrm{t}}^{\alpha} \mathrm{udt} & =\int_{0}^{T} \varphi \mathrm{d}\left({ }_{0} \mathrm{I}_{\mathrm{t}}^{1-\alpha} \mathrm{u}\right) \mathrm{dt}=-\int_{0}^{T} \varphi^{\prime}{ }_{0} \mathrm{I}_{\mathrm{t}}^{1-\alpha} \mathrm{udt} \\
& =-\int_{0}^{T} u_{\mathrm{t}} \mathrm{I}_{\mathrm{T}}^{1-\alpha} \varphi^{\prime} \mathrm{dt}=\int_{0}^{T} u_{\mathrm{t}} \mathrm{D}_{\mathrm{T}}^{\alpha} \varphi d t .
\end{aligned}
$$

On the other hand,

$$
\int_{0}^{T} u_{t} D_{T}^{\alpha} \varphi d t=\int_{0}^{T}{ }_{0} D_{t}^{1-\alpha}{ }_{0} I_{t}^{1-\alpha} u_{t} D_{T}^{\alpha} \varphi d t
$$




$$
\begin{aligned}
& =\int_{0}^{T}{ }_{0} \mathrm{D}_{\mathrm{t}}^{1-\alpha}{ }_{0} \mathrm{I}_{\mathrm{t}}^{1-\alpha} \mathrm{u}\left({ }_{\mathrm{t}} \mathrm{I}_{\mathrm{T}}^{\alpha-1} \varphi^{\prime}\right) \mathrm{dt} \\
& =-\int_{0}^{T} \varphi^{\prime}{ }_{0} \mathrm{I}_{\mathrm{t}}^{\alpha-1}{ }_{0} \mathrm{D}_{\mathrm{t}}^{1-\alpha}{ }_{0} \mathrm{I}_{\mathrm{t}}^{1-\alpha} u d t .
\end{aligned}
$$

Since ${ }_{0} I_{t}^{1-\alpha} u \in{ }_{0} I_{t}^{1-\alpha}\left(L^{1}\right)$, by [20, Lemma 2.5], we have

$$
\int_{0}^{T} u_{t} D_{T}^{\alpha} \varphi d t=-\int_{0}^{T} \varphi^{\prime}{ }_{0} I_{t}^{1-\alpha} u d t=\int_{0}^{T} \varphi\left({ }_{0} I_{t}^{1-\alpha} u\right)^{\prime} d t=\int_{0}^{T} \varphi_{0} D_{t}^{1-\alpha} u d t .
$$

Define fractional type Sobolev space.

$$
E^{\alpha, p}=\left\{u \in L^{p}[0, T]:{ }_{0} D_{t}^{\alpha} u \in L^{p}[0, T]\right\},
$$

with the norm

$$
\|u\|_{\alpha, p}=\left(\left.\left.\int_{0}^{T}\right|_{0} D_{t}^{\alpha} u(t)\right|^{p} d t+\int_{0}^{T}|u(t)|^{p} d t\right)^{1 / p}
$$

Moreover, from [15], it is a reflexive and separable Banach space for $1<p<\infty$. Furthermore, the fractional derivative space $E_{0}^{\alpha, p}$ is defined by the closure of $C_{0}^{\infty}[0, T]$ in the norm of $E^{\alpha, p}$. Clearly, $E_{0}^{\alpha, p} \subset$ $E^{\alpha, p}$ is also a reflexive and separable Banach space. Noting if $\alpha=1, E_{0}^{\alpha, p}$ can turn into the well-known space $W_{0}^{1, p}$. By [19], we know that if $\frac{1}{p}<\alpha \leqslant 1$ and $u \in E_{0}^{\alpha, p}$, then $u(0)=u(T)=0$.

Let $\|\mathfrak{u}\|_{L^{p}}=\left(\int_{0}^{T}|u(t)|^{p} d t\right)^{\frac{1}{p}}$ and $\|\mathfrak{u}\|_{\infty}=\max _{t \in[0, T]}|u(t)|$ be the norm in $L^{p}$ and $C[0, T]$, respectively.

Lemma 2.8 ([18]). Let $0<\alpha \leqslant 1$ and $1<\mathrm{p}<\infty$. For all $\mathrm{u} \in \mathrm{E}_{0}^{\alpha, \mathrm{p}}$, we have

$$
\|u\|_{L^{p}} \leqslant \frac{T^{\alpha}}{\Gamma(\alpha+1)}\left\|_{0} D_{t}^{\alpha} u\right\|_{L^{p}}
$$

Moreover, if $\alpha>\frac{1}{p}$ and $\frac{1}{p}+\frac{1}{q}=1$, then

$$
\|u\|_{\infty} \leqslant \frac{T^{\alpha-1 / q}}{\Gamma(\alpha)(q(\alpha-1)+1)^{1 / q}}\left\|_{0} D_{t}^{\alpha} u\right\|_{L^{p}} .
$$

Based on (2.4), we can consider $\mathrm{E}_{0}^{\alpha, p}$ with respect to the norm

$$
\|\mathrm{u}\|_{\alpha, p}=\left(\left.\left.\int_{0}^{T}\right|_{0} D_{t}^{\alpha} \mathfrak{u}(\mathrm{t})\right|^{p} \mathrm{dt}\right)^{1 / p}=\left\|_{0} D_{\mathrm{t}}^{\alpha} \mathrm{u}\right\|_{\mathrm{L}^{\mathrm{p}}}, \forall \mathfrak{u} \in \mathrm{E}_{0}^{\alpha, p}
$$

and (2.3) is equivalent to (2.5).

Proposition 2.9 ([18]). Let $0<\alpha \leqslant 1$ and $1<p<\infty$. Assume that $\alpha>\frac{1}{p}$ and the sequence $\mathrm{u}_{\mathrm{n}}$ converges weakly to $\mathrm{u}$ in $\mathrm{E}_{0}^{\alpha, p}$, i.e., $\mathrm{u}_{\mathrm{n}} \rightarrow \mathrm{u}$. Then, $\mathrm{u}_{\mathrm{n}} \rightarrow \mathrm{u}$ in $\mathrm{C}[0, \mathrm{~T}]$, i.e., $\left\|\mathrm{u}_{\mathrm{n}}-\mathrm{u}\right\|_{\infty} \rightarrow 0, \mathrm{n} \rightarrow \infty$.

In this paper, we define new norm in $\mathrm{E}_{0}^{\alpha, \mathrm{p}}$ :

$$
\|u\|=\left(\int_{0}^{T}\left|D_{0}^{\alpha} u(t)\right|^{p} d t+\int_{0}^{T} b(t)|u(t)|^{p} d t\right)^{1 / p}
$$

Lemma 2.10. If ess $\inf f_{\mathfrak{t} \in[0, \mathrm{~T}]} \mathrm{b}(\mathrm{t})>-\left(\frac{\Gamma(\alpha+1)}{\mathrm{T}^{\alpha}}\right)^{p}$, the norm $\|\mathrm{u}\|$ is equivalent to the norm $\|\mathrm{u}\|_{\alpha, \mathrm{p}}$. 
Proof. Since ess $\inf _{t \in[0, T]} b(t):=\delta>-\left(\frac{\Gamma(\alpha+1)}{T^{\alpha}}\right)^{p}$, there exists $\omega \in(0,1)$ such that $-\delta \leqslant(1-\omega)\left(\frac{\Gamma(\alpha+1)}{T^{\alpha}}\right)^{p}$. By (2.4), we can obtain

$$
(1-\omega) \int_{0}^{T}\left|D_{0} D_{t}^{\alpha} u(t)\right|^{p} d t \geqslant(1-\omega)\left(\frac{\Gamma(\alpha+1)}{T^{\alpha}}\right)^{p} \int_{0}^{T}|u(t)|^{p} d t \geqslant-\delta \int_{0}^{T}|u(t)|^{p} d t .
$$

Thus, for $u \in E_{0}^{\alpha, p}$, we get

$$
\|u\|^{p} \geqslant\left.\left.\int_{0}^{T}\right|_{0} D_{t}^{\alpha} u(t)\right|^{p} d t+\sigma \int_{0}^{T}|u(t)|^{p} d t \geqslant \omega\|u\|_{\alpha, p}^{p}
$$

On the other hand, we have

$$
\|u\|^{p} \leqslant \int_{0}^{T}\left|{ }_{0} D_{t}^{\alpha} u(t)\right|^{p} d t+\|b\|_{L^{\infty}} \int_{0}^{T}|u(t)|^{p} d t \leqslant\left(\|b\|_{L^{\infty}}\left(\frac{T^{\alpha}}{\Gamma(\alpha+1)}\right)^{p}+1\right)\|u\|_{\alpha, p}^{p} .
$$

Hence, the norm $\|u\|$ is equivalent to the norm $\|u\|_{\alpha, p}$.

Let $v \in \mathrm{E}_{0}^{\alpha, \mathrm{p}}$. Multiplying the two sides of the (1.2) by $v$ and integrating from 0 to $\mathrm{T}$, we have

$$
\begin{gathered}
\int_{0}^{T}{ }_{t} D_{T}^{\alpha}\left(\left.\left.\right|_{0} D_{t}^{\alpha} u(t)\right|^{p-2}{ }_{0} D_{t}^{\alpha} u(t)\right) v(t) d t+\int_{0}^{T} b(t)|u(t)|^{p-2} u(t) v(t) d t \\
=\lambda \int_{0}^{T} f(t, u(t)) v(t) d t+\mu \int_{0}^{T} g(t, u(t)) v(t) d t .
\end{gathered}
$$

Note that

$$
\begin{aligned}
\int_{0}^{T}{ }_{t} D_{T}^{\alpha}\left(\left.l_{0} D_{t}^{\alpha} u(t)\right|^{p-2}{ }_{0} D_{t}^{\alpha} u(t)\right) v(t) d t & =-\int_{0}^{T} v(t) d\left[{ }_{t} I_{T}^{1-\alpha}\left(\left.\left.\right|_{0} D_{t}^{\alpha} u(t)\right|^{p-2}{ }_{0} D_{t}^{\alpha} u(t)\right)\right] \\
& =\int_{0}^{T}{ }_{t} I_{T}^{1-\alpha}\left(\left.\left.\right|_{0} D_{t}^{\alpha} u(t)\right|^{p-2}{ }_{0} D_{t}^{\alpha} u(t)\right) v^{\prime}(t) d t .
\end{aligned}
$$

In view of Proposition 2.6, we can get

$$
\begin{aligned}
\int_{0}^{T}{ }_{t} D_{T}^{\alpha}\left(\left.\left.\right|_{0} D_{t}^{\alpha} u(t)\right|^{p-2}{ }_{0} D_{t}^{\alpha} u(t)\right) v(t) d t & =\int_{0}^{T}\left(\left.l_{0} D_{t}^{\alpha} u(t)\right|^{p-2}{ }_{0} D_{t}^{\alpha} u(t)\right)\left({ }_{0} I_{t}^{1-\alpha} v^{\prime}(t)\right) d t \\
& =\int_{0}^{T}\left|{ }_{0} D_{t}^{\alpha} u(t)\right|^{p-2}{ }_{0} D_{t}^{\alpha} u(t){ }_{0} D_{t}^{\alpha} v(t) d t .
\end{aligned}
$$

As a result, we give the definition of weak solution.

Definition 2.11. Let $u \in E_{0}^{\alpha, p}$ be a weak solution of (1.2) if

$$
\begin{gathered}
\int_{0}^{T}\left|{ }_{0} D_{t}^{\alpha} u(t)\right|^{p-2}{ }_{0} D_{t}^{\alpha} u(t){ }_{0} D_{t}^{\alpha} v(t) d t+\int_{0}^{T} b(t)|u(t)|^{p-2} u(t) v(t) d t \\
-\lambda \int_{0}^{T} f(t, u(t)) v(t) d t-\mu \int_{0}^{T} g(t, u(t)) v(t) d t=0
\end{gathered}
$$

holds for any $v \in \mathrm{E}_{0}^{\alpha, p}$.

Define the functional $\mathrm{I}: \mathrm{E}_{0}^{\alpha, p} \rightarrow \mathbb{R}$ by

$$
I(u)=\frac{1}{p}\|u\|^{p}-\lambda \int_{0}^{T} F(t, u(t)) d t-\mu \int_{0}^{T} G(t, u(t)) d t
$$


where $F(t, u)=\int_{0}^{u} f(t, s) d s$ and $G(t, u)=\int_{0}^{u} g(t, s) d s$. Based on the continuity of $f$, following [31], we have $I \in C^{1}\left(E_{0}^{\alpha, p}, \mathbb{R}\right)$. For any $v \in E_{0}^{\alpha, p}$, one has

$$
\begin{aligned}
\left\langle I^{\prime}(u), v\right\rangle= & \left.\left.\int_{0}^{T}\right|_{0} D_{t}^{\alpha} u(t)\right|^{p-2}{ }_{0} D_{t}^{\alpha} u(t){ }_{0} D_{t}^{\alpha} v(t) d t+\int_{0}^{T} b(t)|u(t)|^{p-2} u(t) v(t) d t \\
& -\lambda \int_{0}^{T} f(t, u(t)) v(t) d t-\mu \int_{0}^{T} g(t, u(t)) v(t) d t .
\end{aligned}
$$

Hence, the weak solutions of problem (1.2) are the corresponding critical points of I.

In order to obtain our main results, we need the following lemmas.

Definition $2.12([9,12])$. Let $E$ be a real Banach space with its dual $E^{*}$ and $I \in C^{1}(E, \mathbb{R})$.

(i) $\left\{u_{n}\right\} \subset E$ has a convergent subsequence if $I\left(u_{n}\right)$ is bounded and $I^{\prime}\left(u_{n}\right) \rightarrow 0$ as $n \rightarrow \infty$, then we say that $\mathrm{I}(\mathrm{u})$ satisfies the Palais-Smale condition ((PS)-condition for short).

(ii) $\left\{u_{n}\right\} \subset E$ has a convergent subsequence if $\mathrm{I}\left(\mathrm{u}_{\mathrm{n}}\right) \rightarrow \mathrm{c}, \mathrm{c} \in \mathbb{R}$ and

$$
\left(1+\left\|u_{n}\right\|\right)\left\|I^{\prime}\left(u_{n}\right)\right\|_{E^{*}} \rightarrow 0, \text { as } n \rightarrow \infty,
$$

then we say that $I(u)$ satisfies the the Cerami condition at the level $c\left((C)_{c}\right.$-condition for short).

Lemma 2.13 ([28]). Let $\mathrm{E}$ be a real Banach space and $\mathrm{I} \in \mathrm{C}^{1}(\mathrm{E}, \mathbb{R})$ satisfies (PS)-condition. If $\mathrm{I}$ is bounded from below, then $\mathrm{c}=\inf _{\mathrm{E}} \mathrm{I}$ is a critical point.

Lemma 2.14 ([12]). Let $\mathrm{E}$ be a real Banach space with its dual $\mathrm{E}^{*}$, and assume that $\mathrm{J} \in \mathrm{C}^{1}(\mathrm{E}, \mathbb{R})$ satisfies

$$
\max \{\mathrm{I}(0), \mathrm{I}(e)\} \leqslant \mu<\eta \leqslant \inf _{\|\mathfrak{u}\|=\rho} \mathrm{I}(\mathfrak{u}),
$$

for some $\rho>0, \mu<\eta$ and $e \in \mathrm{E}$ with $\|e\|>\rho$. Let $\hat{\mathrm{c}} \geqslant \eta$ be characterized by

$$
\hat{\mathrm{c}}=\inf _{\gamma \in \Gamma} \max _{\tau \in[0,1]} \mathrm{I}(\gamma(\tau)),
$$

where $\Gamma=\{\gamma \in \mathrm{C}([0,1], \mathrm{E}): \gamma(0)=0, \gamma(1)=\mathrm{e}\}$ is the set of continuous paths joining 0 and $\mathrm{e}$, then there exists a sequence $\left\{u_{n}\right\} \subset$ E such that

$$
\mathrm{I}\left(\mathrm{u}_{\mathrm{n}}\right) \rightarrow \hat{\mathrm{c}} \geqslant \eta, \text { and }\left(1+\left\|\mathrm{u}_{\mathrm{n}}\right\|\right)\left\|\mathrm{I}^{\prime}\left(\mathrm{u}_{\mathrm{n}}\right)\right\|_{\mathrm{E}^{*}} \rightarrow 0 \text { as } \mathrm{n} \rightarrow \infty .
$$

Lemma 2.15 ([14]). Let $\mathrm{E}$ be a real Banach space and $\mathrm{P}$ be a cone in $\mathrm{E}$. Suppose that $\Omega_{1}$ and $\Omega_{2}$ are open subsets of $E$ such that $\theta \in \Omega_{1} \subset \overline{\Omega_{1}} \subset \Omega_{2}$ and let

$$
\mathrm{T}: \mathrm{P} \cap\left(\overline{\Omega_{2}} \backslash \Omega_{1}\right) \rightarrow \mathrm{P},
$$

be a completely continuous operator such that

(i) $\|\mathrm{Tu}\| \leqslant\|u\|$ for $\mathrm{u} \in \mathrm{P} \cap \partial \Omega_{1}$, and $\|\mathrm{Tu}\| \geqslant\|\mathrm{u}\|$ for $\mathrm{u} \in \mathrm{P} \cap \partial \Omega_{2}$; or

(ii) $\|T u\| \leqslant\|u\|$ for $u \in P \cap \partial \Omega_{2}$, and $\|T u\| \geqslant\|u\|$ for $u \in P \cap \partial \Omega_{1}$.

Then $\mathrm{T}$ has a fixed point in $\mathrm{P} \cap\left(\overline{\Omega_{2}} \backslash \Omega_{1}\right)$.

\section{The main results of (1.2)}

Let $\mathbb{R}^{+}=\{x \in \mathbb{R}: x \geqslant 0\}$. The constant $c$ means the different constant in different parts. Define $h^{ \pm}(t)=\max \{ \pm h(t), 0\}$.

Theorem 3.1. Assume that $u \in \mathrm{E}_{0}^{\alpha, \mathrm{p}}, \frac{1}{\mathrm{p}}<\alpha \leqslant 1$, ess $\inf _{\mathrm{t} \in[0, \mathrm{~T}]} \mathrm{b}(\mathrm{t})>-\left(\frac{\Gamma(\alpha+1)}{\mathrm{T}^{\alpha}}\right)^{p}$ and the following conditions hold: 
(g1) There exists a constant $\gamma \in(1, \mathrm{p})$ and a function $\mathrm{h}(\mathrm{t}) \in \mathrm{L}^{1}\left([0, \mathrm{~T}], \mathbb{R}^{+}\right)$such that

$$
|g(t, u)| \leqslant \gamma h(t)|u|^{\gamma-1} .
$$

$$
\limsup _{|\mathfrak{u}| \rightarrow \infty} \frac{f(t, u)}{|\mathfrak{u}|^{p-1}}=0, \text { uniformly for } \mathrm{t} \in[0, \mathrm{~T}]
$$

(f2) There exists a function $v \in \mathrm{E}_{0}^{\alpha, \mathrm{p}}$ such that

$$
\int_{0}^{T} F(t, v) d t>0
$$

Then there exists a positive constant $\lambda_{*}$ such that if $\lambda>\lambda_{*}$, the problem (1.2) has at least one nontrivial weak solutions.

Corollary 3.2. If (f2) is replaced by the following condition in Theorem 3.1:

(f3) There exist constants $\mathrm{k} \in(1, \gamma)$ and $\mathrm{d}, \sigma>0$ such that for any $\mathrm{t} \in[0, \mathrm{~T}]$,

$$
F(t, u) \geqslant d|u|^{k}, \quad|u| \leqslant \sigma .
$$

Then the problem (1.2) has at least one nontrivial weak solution without limit to $\lambda$.

Let us introduce some lemmas.

Lemma 3.3. Assume that (g1) and (f2) hold, $\frac{1}{\mathrm{p}}<\alpha \leqslant 1$ and ess inf $\mathrm{t} \in[0, \mathrm{~T}]_{\mathrm{b}} \mathrm{b}(\mathrm{t})>-\left(\frac{\Gamma(\alpha+1)}{\mathrm{T}^{\alpha}}\right)^{\mathrm{p}}$, if $\mathrm{u}_{*} \in \mathrm{E}_{0}^{\alpha, \mathrm{p}}$ is a critical point of $\mathrm{I}(\mathrm{u})$ such that $\mathrm{I}\left(\mathrm{u}_{*}\right)=\inf _{\mathrm{E}_{0}^{\alpha, p}} \mathrm{I}(\mathrm{u})=\beta$, where $\beta$ is the critical value, then $\mathrm{u}_{*}$ is a nontrivial weak solution of problem (1.2) for $\lambda>\lambda_{*}$.

Proof. By (f2), there exists a function $v \in \mathrm{E}_{0}^{\alpha, \mathrm{p}}$ such that

$$
\int_{0}^{T} F(t, v(t)) d t>0
$$

From (g1), we have

$$
|G(t, u)| \leqslant \int_{0}^{u}|g(t, \tau)| d \tau \leqslant \int_{0}^{u} \gamma h(t)|\tau|^{\gamma-1} d \tau \leqslant h(t)|u|^{\gamma}
$$

and

$$
\begin{aligned}
I(v) & =\frac{1}{p}\|v\|^{p}-\lambda \int_{0}^{T} F(t, v(t)) d t-\mu \int_{0}^{T} G(t, v(t)) d t \\
& \leqslant \frac{1}{p}\|v\|^{p}-\lambda \int_{0}^{T} F(t, v(t)) d t+\mu \int_{0}^{T} h(t)|v(t)|^{\gamma} d t .
\end{aligned}
$$

Hence, we can find a

$$
\lambda_{*}=\frac{\frac{1}{p}\|v\|^{p}+\mu \int_{0}^{T} h(t)|v(t)|^{\gamma} d t}{\int_{0}^{\top} F(t, v(t)) d t}>0 .
$$

If $\lambda>\lambda_{*}$, we have $J(v)<0$. So, $J\left(u_{*}\right)=\beta<0$. Hence, $u_{*}$ is a nontrivial weak solution of problem (1.2). 
Lemma 3.4. Assume that (g1) and (f3) hold, $\frac{1}{\mathrm{p}}<\alpha \leqslant 1$ and ess $\inf _{\mathrm{t} \in[0, \mathrm{~T}]} \mathrm{b}(\mathrm{t})>-\left(\frac{\Gamma(\alpha+1)}{\mathrm{T}^{\alpha}}\right)^{\mathrm{p}}$, then the conclusion of Lemma 3.3 is also true without limit to $\lambda$.

Proof. Let $\mathrm{u}_{0} \in \mathrm{E}_{0}^{\alpha, p} \backslash\{0\}$ with $\left\|\mathrm{u}_{0}\right\|_{\infty} \leqslant 1$. Following (g1) and (f3), for $0<\mathrm{r}<\sigma$, we have

$$
\begin{aligned}
\mathrm{I}\left(\mathrm{ru} \mathrm{u}_{0}\right) & =\frac{1}{\mathrm{p}}\left\|r \mathrm{u}_{0}\right\|^{\mathrm{p}}-\lambda \int_{0}^{T} \mathrm{~F}\left(\mathrm{t}, \mathrm{ru} \mathrm{u}_{0}(\mathrm{t})\right) \mathrm{dt}-\mu \int_{0}^{T} \mathrm{G}\left(\mathrm{t}, \mathrm{ru} \mathrm{u}_{0}(\mathrm{t})\right) \mathrm{dt} \\
& \leqslant \frac{\mathrm{r}^{\mathrm{p}}}{\mathrm{p}}\left\|\mathrm{u}_{0}(\mathrm{t})\right\|^{\mathrm{p}}-k \mathrm{r}^{\mathrm{K}} \lambda \int_{0}^{T}\left|\mathrm{u}_{0}(\mathrm{t})\right|^{\mathrm{K}} \mathrm{dt}+\mu \mathrm{r}^{\gamma} \int_{0}^{T} \mathrm{~h}(\mathrm{t})\left|\mathrm{u}_{0}(\mathrm{t})\right|^{\gamma} \mathrm{dt} .
\end{aligned}
$$

Since $k \in(1, \gamma)$, for small enough $r$, we can get $I\left(r u_{0}\right)<0$. Hence, $J\left(u_{*}\right)=\beta<0$. Therefore, $u_{*}$ is a nontrivial weak solution of problem (1.2).

Lemma 3.5. If $\mathrm{u} \in \mathrm{E}_{0}^{\alpha, p}, \frac{1}{\mathrm{p}}<\alpha \leqslant 1$, ess $\inf _{\mathrm{t} \in[0, \mathrm{~T}]} \mathrm{b}(\mathrm{t})>-\left(\frac{\Gamma(\alpha+1)}{\mathrm{T}^{\alpha}}\right)^{\mathrm{p}}$, (f1) and (g1) hold, then $\mathrm{I}(\mathrm{u})$ is bounded from below.

Proof. Based on (f1), for any $\varepsilon>0$, there exists a constant $\delta>0$ such that for $t \in[0, T]$,

$$
\mathrm{F}(\mathrm{t}, \mathrm{u}) \leqslant \frac{\varepsilon}{\mathrm{p}}|\mathrm{u}|^{\mathrm{p}}, \quad|\mathrm{u}| \geqslant \delta
$$

By the continuity of $f$, there exists a constant $V_{\varepsilon} \in L^{1}\left([0, T], \mathbb{R}^{+}\right)$such that $F(t, u) \leqslant V_{\varepsilon}(t)$ for $(t, u) \in$ $[0, T] \times[-\delta, \delta]$. Thus, we have

$$
F(t, u) \leqslant \frac{\varepsilon}{p}|u|^{p}+V_{\varepsilon}(t), \quad \text { for }(t, u) \in[0, T] \times \mathbb{R} .
$$

From (g1), we have

$$
\begin{aligned}
I(u) & =\frac{1}{p}\|u\|^{p}-\lambda \int_{0}^{T} F(t, u(t)) d t-\mu \int_{0}^{T} G(t, u(t)) d t \\
& \geqslant \frac{1}{p}\|u\|^{p}-\lambda \frac{\varepsilon}{p} \int_{0}^{T}|u(t)|^{p} d t-\mu \int_{0}^{T} h(t)|u(t)|^{\gamma} d t-\lambda\left\|V_{\varepsilon}\right\|_{L^{1}} .
\end{aligned}
$$

Since the embedding $E_{0}^{\alpha, p} \hookrightarrow C[0, T]$ is compact, there exists a constant $S$ such that $\|u\|_{\infty} \leqslant S\|u\|$. Hence, we have

$$
\mathrm{I}(\mathrm{u}) \geqslant \frac{1}{\mathrm{p}}\|\mathrm{u}\|^{\mathrm{p}}-\lambda \mathrm{TS} \mathrm{S}^{\mathrm{p}} \frac{\varepsilon}{\mathrm{p}}\|\mathrm{u}\|^{\mathrm{p}}-\mu \mathrm{S}^{\gamma}\|\mathrm{h}\|_{\mathrm{L}^{1}}\|\mathrm{u}\|^{\gamma}-\lambda\left\|\mathrm{V}_{\mathcal{\varepsilon}}\right\|_{\mathrm{L}^{1}}
$$

Choosing $\varepsilon=\frac{1}{2 \lambda S^{p}}$, we can get

$$
\mathrm{I}(\mathrm{u}) \geqslant \frac{1}{2 p}\|u\|^{p}-\mu S^{\gamma}\|\mathrm{h}\|_{\mathrm{L}^{1}}\|u\|^{\gamma}-\lambda\left\|\mathrm{V}_{\mathcal{E}}\right\|_{\mathrm{L}^{1}} .
$$

Since $1<\gamma<p$, we have $\mathrm{I}(\mathrm{u}) \rightarrow \infty$ as $\|\mathrm{u}\| \rightarrow \infty$, so $\mathrm{I}(\mathrm{u})$ is coercive. Therefore, $\mathrm{I}(\mathrm{u})$ is bounded from below.

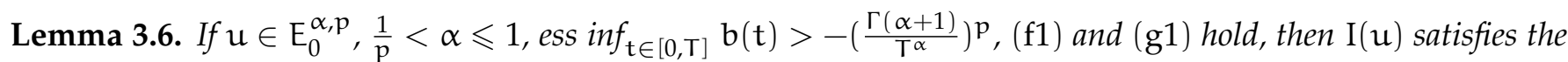
(PS)-condition.

Proof. Let $\left\{u_{n}\right\} \subset E_{0}^{\alpha, p}$ such that $\left\{I\left(u_{n}\right)\right\}$ is bounded and $I^{\prime}\left(u_{n}\right) \rightarrow 0$ as $n \rightarrow \infty$. Since $\mathrm{I}\left(u_{n}\right)$ is coercive, we can get that $\left\{u_{n}\right\}$ is bounded in $E_{0}^{\alpha, p}$. Based on the fact that $E_{0}^{\alpha, p}$ is a reflexive Banach space, $\left\{u_{n}\right\}$ has a convergent subsequence (named again by $\left\{u_{n}\right\}$ ) such that $u_{n} \rightarrow u$ in $E_{0}^{\alpha, p}$, so $u_{n} \rightarrow u$ uniformly in $C[0, T]$. Thus, we have

$$
\int_{0}^{T}\left(f\left(t, u_{n}(t)\right)-f(t, u(t))\right)\left(u_{n}(t)-u(t)\right) d t \rightarrow 0, \quad n \rightarrow \infty,
$$




$$
\begin{gathered}
\int_{0}^{T}\left(g\left(t, u_{n}(t)\right)-g(t, u(t))\right)\left(u_{n}(t)-u(t)\right) d t \rightarrow 0, \quad n \rightarrow \infty, \\
\int_{0}^{T} b(t)\left(\phi_{p}\left(u_{n}\right)-\phi_{p}(u)\right)\left(u_{n}-u\right) d t \rightarrow 0, \quad n \rightarrow \infty .
\end{gathered}
$$

By I' $\left(u_{n}\right) \rightarrow 0$ and $u_{n} \rightarrow u$, we can obtain

$$
\left\langle\mathrm{I}^{\prime}\left(\mathrm{u}_{\mathrm{n}}\right)-\mathrm{I}^{\prime}(\mathrm{u}), \mathrm{u}_{\mathrm{n}}-\mathrm{u}\right\rangle \rightarrow 0, \quad \mathrm{n} \rightarrow \infty
$$

Thus, we have

$$
\begin{aligned}
\left\langle I^{\prime}\left(u_{n}\right)-I^{\prime}(u), u_{n}-u\right\rangle= & \int_{0}^{T}\left(\phi_{p}\left({ }_{0} D_{t}^{\alpha} u_{n}(t)\right)-\phi_{p}\left({ }_{0} D_{t}^{\alpha} u(t)\right)\right)\left({ }_{0} D_{t}^{\alpha} u_{n}(t)-{ }_{0} D_{t}^{\alpha} u(t)\right) d t \\
& +\int_{0}^{T} b(t)\left(\phi_{p}\left(u_{n}\right)-\phi_{p}(u)\right)\left(u_{n}-u\right) d t \\
& -\lambda \int_{0}^{T}\left(f\left(t, u_{n}(t)\right)-f(t, u(t))\right)\left(u_{n}(t)-u(t)\right) d t \\
& -\mu \int_{0}^{T}\left(g\left(t, u_{n}(t)\right)-g(t, u(t))\right)\left(u_{n}(t)-u(t)\right) d t .
\end{aligned}
$$

Based on [34], we have

$$
\begin{gathered}
\int_{0}^{T}\left(\phi_{p}\left({ }_{0} D_{t}^{\alpha} u_{n}(t)\right)-\phi_{p}\left({ }_{0} D_{t}^{\alpha} u(t)\right)\right)\left({ }_{0} D_{t}^{\alpha} u_{n}(t)-{ }_{0} D_{t}^{\alpha} u(t)\right) d t \\
\geqslant \begin{cases}c \int_{0}^{T}\left|{ }_{0} D_{t}^{\alpha} u_{n}(t)-{ }_{0} D_{t}^{\alpha} u(t)\right|^{p} d t, & p \geqslant 2, \\
c \int_{0}^{T} \frac{{ }_{0} D_{t}^{\alpha} u_{n}(t)-\left.{ }_{0} D_{t}^{\alpha} u(t)\right|^{2}}{\left(l_{0} D_{t}^{\alpha} u_{n}(t)|+|_{0} D_{t}^{\alpha} u(t) \mid\right)^{2-p}} d t, & 1<p<2 .\end{cases}
\end{gathered}
$$

If $p \geqslant 2$, then (3.1), (3.2), (3.3), (3.4), (3.5) yield that $\left\|u_{n}-u\right\| \rightarrow 0, n \rightarrow \infty$. If $1<p<2$, by hölder inequality, we have

$$
\left.\int_{0}^{T}\right|_{0} D_{t}^{\alpha} u_{n}(t)-\left.{ }_{0} D_{t}^{\alpha} u(t)\right|^{p} d t \leqslant c\left(\int_{0}^{T} \frac{\left|{ }_{0} D_{t}^{\alpha} u_{n}(t)-{ }_{0} D_{t}^{\alpha} u(t)\right|^{2}}{\left(l_{0} D_{t}^{\alpha} u_{n}(t)|+|_{0} D_{t}^{\alpha} u(t) \mid\right)^{2-p}} d t\right)^{\frac{p}{2}}\left(\left\|u_{n}\right\|+\|u\|\right)^{\frac{p(2-p)}{2}} .
$$

Thus, we can obtain that

$$
\begin{gathered}
\int_{0}^{T}\left(\phi_{p}\left({ }_{0} D_{t}^{\alpha} u_{n}(t)\right)-\phi_{p}\left({ }_{0} D_{t}^{\alpha} u(t)\right)\right)\left({ }_{0} D_{t}^{\alpha} u_{n}(t)-{ }_{0} D_{t}^{\alpha} u(t)\right) d t \\
\geqslant \frac{c}{\left(\left\|u_{n}\right\|+\|u\|\right)^{2-p}}\left(\int_{0}^{T} l_{0} D_{t}^{\alpha} u_{n}(t)-\left.{ }_{0} D_{t}^{\alpha} u(t)\right|^{p} d t\right)^{\frac{2}{p}} .
\end{gathered}
$$

Thus, we have $\left\|u_{n}-u\right\| \rightarrow 0, n \rightarrow \infty$. Thus, $u_{n} \rightarrow u$ in $E_{0}^{\alpha, p}$. Therefore, $I(u)$ satisfies the (PS)condition.

Proof of Theorem 3.1 and Corollary 3.2.

In view of Lemma 3.3 (or Lemma 3.4), Lemma 3.5 and Lemma 3.6, by Lemma 2.13, the conclusion of Theorem 3.1 (or Corollary 3.2) is established immediately. 


\subsection{A special case}

In this part, we consider a special concave-convex case as follows.

$$
\left\{\begin{array}{l}
{ }_{t} D_{T}^{\alpha} \phi_{p}\left({ }_{0} D_{t}^{\alpha} u(t)\right)+b(t) \phi_{p}(u(t))=\lambda m a(t)|u(t)|^{m-2} u(t)+\mu \gamma h(t)|u(t)|^{\gamma-2} u(t), \quad \text { a.e. } t \in(0, T), \\
u(0)=u(T)=0,
\end{array}\right.
$$

where $\mathrm{a}(\mathrm{t}) \in \mathrm{L}^{1}\left([0, \mathrm{~T}], \mathbb{R}^{+}\right) \backslash\{0\}, \mathrm{h}(\mathrm{t}) \in \mathrm{C}([0, \mathrm{~T}], \mathbb{R}) \backslash\{0\}, 1<\gamma<\mathrm{p}<\mathrm{m}$.

Remark 3.7. Note that $h(t)$ may be a sign-changing function.

Theorem 3.8. Assume that $\mathrm{u} \in \mathrm{E}_{0}^{\alpha, p}, \frac{1}{\mathrm{p}}<\alpha \leqslant 1$, ess inf $\mathrm{t}_{\mathrm{t} \in[0, \mathrm{~T}]} \mathrm{b}(\mathrm{t})>-\left(\frac{\Gamma(\alpha+1)}{\mathrm{T}^{\alpha}}\right)^{\mathrm{p}}$. Then there exists a positive constant $\mu^{*}$ such that if $\mu \in\left[0, \mu^{*}\right)$, the problem (3.6) has at least one nontrivial weak solution.

To begin with, we need the following lemmas.

Lemma 3.9. If ess inf $f_{t \in[0, T]} b(t)>-\left(\frac{\Gamma(\alpha+1)}{T^{\alpha}}\right)^{p}$, there exist constants $\rho, \eta, \mu^{*}>0$ such that $\left.I\right|_{\partial B_{\rho} \cap E_{0}^{\alpha, p} \geqslant \eta \text { for }}$ $\mu \in\left[0, \mu^{*}\right)$.

Proof. For $u \in \mathrm{E}_{0}^{\alpha, \mathrm{p}}$, we can obtain

$$
\begin{aligned}
\mathrm{I}(\mathrm{u}) & =\frac{1}{p}\|u\|^{p}-\lambda \int_{0}^{T} a(t)|u(t)|^{m} d t-\mu \int_{0}^{T} h(t)|u(t)|^{\gamma} d t \\
& \geqslant \frac{1}{p}\|u\|^{p}-\lambda \int_{0}^{T} a(t)|u(t)|^{m} d t-\mu \int_{0}^{T} h^{+}(t)|u(t)|^{\gamma} d t \\
& \geqslant \frac{1}{p}\|u\|^{p}-\lambda S^{m}\|a\|_{L^{1}}\|u(t)\|^{m}-\mu S^{\gamma}\left\|h^{+}\right\|_{L^{1}}\|u\|^{\gamma} \\
& =\|u\|^{\gamma}\left(\frac{1}{p}\|u\|^{p-\gamma}-\lambda S^{m}\|a\|_{L^{1}}\|u\|^{m-\gamma}-\mu S^{\gamma}\left\|h^{+}\right\|_{L^{1}}\right) .
\end{aligned}
$$

Let

$$
y(t)=\frac{1}{p} t^{p-\gamma}-\lambda S^{m} t^{m-\gamma}\|a\|_{L^{1},} \quad t \geqslant 0 .
$$

By simple calculation, we can find a $\rho=\left[\frac{p-\gamma}{p \lambda S^{m}(m-\gamma)\|a\|_{L^{1}}}\right]^{\frac{1}{m-p}}$ such that

$$
y(\rho)=\max _{t \geqslant 0} y(t)=\frac{m-p}{p(m-\gamma)}\left[\frac{p-\gamma}{p \lambda S^{m}(m-\gamma)\|a\|_{L^{1}}}\right]^{\frac{p-\gamma}{m-p}}>0 .
$$

Thus, there exists

$$
\mu^{*}=\frac{m-p}{p S^{\gamma}\left\|h^{+}\right\|_{L^{1}}(m-\gamma)}\left[\frac{p-\gamma}{p \lambda S^{m}(m-\gamma)\|a\|_{L^{1}}}\right]^{\frac{p-\gamma}{m-p}} .
$$

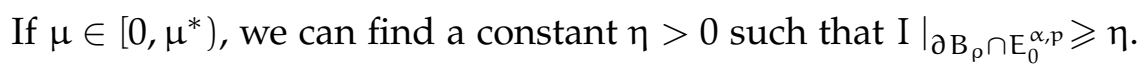

Lemma 3.10. If ess $\inf _{\mathrm{t} \in[0, \mathrm{~T}]} \mathrm{b}(\mathrm{t})>-\left(\frac{\Gamma(\alpha+1)}{\mathrm{T}^{\alpha}}\right)^{p}$, there exists an $\mathrm{e} \in \mathrm{E}_{0}^{\alpha, \mathrm{p}}$ with $\|\mathrm{e}\|>\rho$ such that $\mathrm{I}(\mathrm{e})<0$.

Proof. Let $s \in \mathbb{R}^{+} \backslash\{0\}$, for given $u \in \mathrm{E}_{0}^{\alpha, p}$, we have

$$
\begin{aligned}
I(s u) & =\frac{1}{p}\|s u\|^{p}-\lambda \int_{0}^{T} a(t)|s u(t)|^{m} d t-\mu \int_{0}^{T} h(t)|s u(t)|^{\gamma} d t \\
& =\frac{s^{p}}{p}\|u\|^{p}-\lambda s^{m} \int_{0}^{T} a(t)|u(t)|^{m} d t-\mu s^{\gamma} \int_{0}^{T} h(t)|u(t)|^{\gamma} d t .
\end{aligned}
$$

Since $\mathrm{m}>\mathrm{p}>\gamma$, we have $\mathrm{I}(\mathrm{su}) \rightarrow-\infty$ as $s \rightarrow \infty$. Hence, there exists an $e \in \mathrm{E}_{0}^{\alpha, p}$ with $\|e\|>\rho$ such that $\mathrm{I}(e)<0$. 


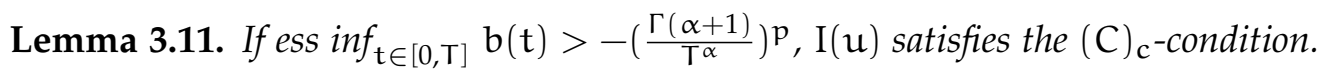

Proof. Let $\left\{u_{n}\right\} \subset E_{0}^{\alpha, p}$ such that $\mathrm{I}\left(\mathrm{u}_{\mathrm{n}}\right) \rightarrow \mathrm{c}$ and $\left(1+\left\|\mathrm{u}_{\mathrm{n}}\right\|\right)\left\|\mathrm{I}^{\prime}\left(\mathrm{u}_{\mathrm{n}}\right)\right\|_{\left(\mathrm{E}_{0}^{\alpha, p}\right)^{*}} \rightarrow 0$ as $\mathrm{n} \rightarrow \infty$. Then, there exists a constant $c>0$ such that

$$
\left|\mathrm{I}\left(\mathrm{u}_{\mathrm{n}}\right)\right| \leqslant c,\left(1+\left\|\mathrm{u}_{\mathrm{n}}\right\|\right)\left\|\mathrm{I}^{\prime}\left(\mathrm{u}_{\mathrm{n}}\right)\right\|_{\left(\mathrm{E}_{0}^{\alpha, p}\right)^{*}} \leqslant \mathrm{c} .
$$

Thus, we have

$$
\begin{aligned}
(m+1) c \geqslant m I\left(u_{n}\right)-\left\langle I^{\prime}\left(u_{n}\right), u_{n}\right\rangle & =\left(\frac{m}{p}-1\right)\left\|u_{n}\right\|^{p}-\mu(m-\gamma) \int_{0}^{T} h(t)|u(t)|^{\gamma} d t \\
& \geqslant \frac{m-p}{p}\left\|u_{n}\right\|^{p}-\mu(m-\gamma) S^{\gamma}\left\|h^{+}\right\|_{L^{1}}\|u\|^{\gamma},
\end{aligned}
$$

which together with $m>p>\gamma$ yields that $\left\{u_{n}\right\}$ is bounded. By similar arguments as Lemma 3.6, $\mathrm{I}(\mathfrak{u})$ meets the $(\mathrm{C})_{\mathrm{c}}$-condition.

Proof of Theorem 3.8.

Based on Lemmas 3.9, 3.10 and 3.11, the conclusion of Theorem 3.8 is true.

\section{The main results of $(1.3)$}

Let

$$
E=\{u(t) \in C[-\tau, T]: u(t) \geqslant 0 \text { and satisfies boundary conditions of (1.3)\}, }
$$

be equipped with norm $\|u\|=\sup \{|u(t)|: t \in[-\tau, T]\}$, it is clear that $(E,\|\cdot\|)$ is a Banach space. To begin with, we need the following important lemmas. The following lemma comes form Lemma 2.3 of Lan and Lin [23].

Lemma 4.1 ([23]). Let $\sigma \in(0,1)$. Then the following assertions hold.

(i) ${ }_{0} I_{\mathrm{t}}^{\sigma}$ maps $\mathrm{AC}[0, \mathrm{~T}]$ to $\mathrm{AC}[0, \mathrm{~T}]$.

(ii) For each $\mathrm{y} \in \mathrm{AC}[0, \mathrm{~T}],{ }_{0} \mathrm{I}_{\mathrm{t} 0}^{\sigma} \mathrm{D}_{\mathrm{t}}^{\sigma} \mathrm{y}(\mathrm{t})=\mathrm{y}(\mathrm{t})$ for a.e. $\mathrm{t} \in[0, \mathrm{~T}]$.

The idea of Lemma 4.2 mainly comes from Theorem 2.4 and Remark 2.5 of Lan and Lin [23].

Lemma 4.2. Assume that $\mathrm{y} \in \mathrm{AC}[0, \mathrm{~T}]$ and $\mathrm{u} \in \mathrm{AC}^{3}[0, \mathrm{~T}]$. Then the problem

$$
\left\{\begin{array}{l}
{ }_{0}^{c} D_{t}^{\beta} \phi_{p}\left({ }_{0}^{c} D_{t}^{\alpha} u(t)\right)-y(t)=0, \quad \text { a.e. } t \in(0, T), 2<\alpha, \beta \leqslant 3 \\
u(0)=u^{\prime}(T)=u^{\prime \prime}(0)=0, \\
\left.\phi_{p}\left({ }_{0}^{c} D_{t}^{\alpha} u(t)\right)\right|_{t=0}=\left.\left(\phi_{p}\left({ }_{0}^{c} D_{t}^{\alpha} u(t)\right)\right)^{\prime}\right|_{t=T}=\left.\left(\phi_{p}\left({ }_{0}^{c} D_{t}^{\alpha} u(t)\right)\right)^{\prime \prime}\right|_{t=0}=0,
\end{array}\right.
$$

is equivalent to the fractional integral equation

$$
\begin{aligned}
u(t)= & -\frac{1}{\Gamma(\alpha)} \int_{0}^{t}(t-s)^{\alpha-1} \phi_{q}\left(-\frac{1}{\Gamma(\beta)} \int_{0}^{s}(s-\tau)^{\beta-1} y(\tau) d \tau+\frac{1}{\Gamma(\beta-1)} \int_{0}^{T} s(T-\tau)^{\beta-2} y(\tau) d \tau\right) d s \\
& +\frac{1}{\Gamma(\alpha-1)} \int_{0}^{T} t(T-s)^{\alpha-1} \phi_{q}\left(-\frac{1}{\Gamma(\beta)} \int_{0}^{s}(s-\tau)^{\beta-1} y(\tau) d \tau+\frac{1}{\Gamma(\beta-1)} \int_{0}^{T} s(T-\tau)^{\beta-2} y(\tau) d \tau\right) d s .
\end{aligned}
$$

Proof. If $\alpha=3$ or $\beta=3$ or $\alpha=\beta=3$, it becomes integer derivative and the proof is normal and clear, so we focus on the case of $2<\alpha, \beta<3$. First, base on basic proposition of fractional calculus, we have

$$
\phi_{p}\left({ }_{0}^{c} D_{t}^{\alpha} u(t)\right)=\frac{1}{\Gamma(\beta)} \int_{0}^{t}(t-s)^{\beta-1} \mathfrak{y}(s) d s+c_{1}+c_{2} t+c_{3} t^{2}
$$


By boundary condition of (4.1), we can obtain $c_{1}=0$,

$$
c_{2}=-\frac{1}{\Gamma(\beta-1)} \int_{0}^{T}(T-s)^{\beta-2} y(s) d s
$$

Moreover, we know that

$$
\phi_{p}\left({ }_{0}^{c} D_{t}^{\alpha} u(t)\right)^{\prime \prime}=\frac{1}{\Gamma(\beta-2)} \int_{0}^{t}(t-s)^{\beta-3} y(s) d s+c_{3}
$$

From [32, Lemma 2.1], for $\beta-2 \in(0,1)$, we know that ${ }_{0} \mathrm{I}_{\mathrm{t}}^{\beta-2}$ maps $\mathrm{L}(0, \mathrm{~T})$ into $\mathrm{F}_{0}^{\beta-2}(0, \mathrm{~T})$ and

$$
\left(\phi_{p}\left({ }_{0}^{c} D_{t}^{\alpha} u(t)\right)\right)^{\prime \prime} \in F_{0}^{\beta-2}(0, T)^{\prime},
$$

where

$$
\mathrm{F}_{0}^{\beta-2}(0, \mathrm{~T})=\left\{v \in \mathrm{L}(0, \mathrm{~T}):{ }_{0} \mathrm{I}_{\mathrm{t}}^{3-\beta} v \in A C[0, \mathrm{~T}] \text { and }{ }_{0} \mathrm{I}_{\mathrm{t}}^{3-\beta} v(0)=0\right\}
$$

Therefore, we have $\left.{ }_{0} I_{t}^{\beta-2} y(t)\right|_{t=0}=0$. So, $\left.\left(\phi_{p}\left({ }_{0}^{c} D_{t}^{\alpha} u(t)\right)\right)^{\prime \prime}\right|_{t=0}=c_{3}=0$. Moreover, for $t \in[0, T]$

$$
\left|\frac{1}{\Gamma(\beta-2)} \int_{0}^{t}(t-s)^{\beta-3} y(s) d s\right| \leqslant \frac{T^{\beta-2}}{\Gamma(\beta-1)}\|y\|,
$$

which together with finiteness of $c_{2}$ yields that $\max \left\{\left(\phi_{p}\left({ }_{0}^{c} D_{t}^{\alpha} \mathfrak{u}(t)\right)\right)^{\prime \prime}: t \in[0, T]\right\}$ is finite. Define

$$
w(t):=\phi_{\mathrm{q}}\left(-\frac{1}{\Gamma(\beta)} \int_{0}^{\mathrm{t}}(\mathrm{t}-\mathrm{s})^{\beta-1} \mathrm{y}(\mathrm{s}) \mathrm{d} s+\frac{1}{\Gamma(\beta-1)} \int_{0}^{\mathrm{T}} \mathrm{t}(\mathrm{T}-\mathrm{s})^{\beta-2} \mathrm{y}(\mathrm{s}) \mathrm{ds}\right) .
$$

Applying the operator $\phi_{\mathrm{q}}$ on both sides of (4.3), by proposition of $\phi_{\mathrm{q}}(-\mathfrak{u})=-\phi_{\mathrm{q}}(\mathfrak{u})$ for $u \in \mathbb{R}$, we can obtain

$$
u(t)=-\frac{1}{\Gamma(\alpha)} \int_{0}^{t}(t-s)^{\alpha-1} w(s) d s+c_{4}+c_{5} t+c_{6} t^{2}
$$

By boundary condition of (4.1), we have $c_{4}=0$ and

$$
c_{5}=\frac{1}{\Gamma(\alpha-1)} \int_{0}^{T}(T-s)^{\alpha-2} w(s) d s .
$$

Since $y \in A C[0, T]$, clearly, $w(t) \in A C[0, T]$. Note that

$$
\left|-\frac{1}{\Gamma(\beta)} \int_{0}^{t}(t-s)^{\beta-1} y(s) d s+\frac{1}{\Gamma(\beta-1)} \int_{0}^{T} t(T-s)^{\beta-2} y(s) d s\right| \leqslant\left(\frac{T^{\beta}}{\Gamma(\beta+1)}+\frac{T^{\beta-1}}{\Gamma(\beta)}\right)\|y\| .
$$

Based on the fact that ${ }_{0} \mathrm{I}_{\mathrm{t}}^{\alpha-2}$ maps $\mathrm{L}(0, \mathrm{~T})$ into $\mathrm{F}_{0}^{\alpha-2}(0, \mathrm{~T})$ and $\mathrm{u}^{\prime \prime}(\mathrm{t}) \in \mathrm{F}_{0}^{\alpha-2}(0, \mathrm{~T})$, we have $\mathrm{u}^{\prime \prime}(0)=\mathrm{c}_{6}=0$ and

$$
\left|\frac{1}{\Gamma(\alpha-2)} \int_{0}^{t}(t-s)^{\alpha-3} w(s) d s\right| \leqslant 2^{q-1} \frac{T^{\alpha-2}}{\Gamma(\alpha-1)}\left(\frac{T^{\beta(q-1)}}{(\Gamma(\beta+1))^{q-1}}+\frac{T^{(\beta-1)(q-1)}}{(\Gamma(\beta))^{q-1}}\right)\|y\|^{q-1},
$$

by basic inequality $(a+b)^{\gamma} \leqslant 2^{\gamma}\left(a^{\gamma}+b^{\gamma}\right)$ where $a, b, \gamma$ are positive number. Thus, we have

$$
\max \left\{\mathrm{u}^{\prime \prime}(\mathrm{t}): \mathrm{t} \in[0, \mathrm{~T}]\right\},
$$

is finite. Therefore, if $u(t)$ is a solution of (4.1), then $u(t)$ satisfies (4.2). Conversely, by (4.4) and Definition 2.2, we have

$$
\mathrm{u}^{\prime \prime \prime}(\mathrm{t})=-\left({ }_{0} \mathrm{I}_{\mathrm{t}}^{\alpha-2} \mathfrak{w}(\mathrm{t})\right)^{\prime}=-{ }_{0} \mathrm{D}_{\mathrm{t}}^{3-\alpha} \mathfrak{w}(\mathrm{t})
$$


Since $w(t) \in A C[0, T]$, by (ii) of Lemma 4.1 and $3-\alpha \in(0,1)$, we can get, for a.e. $t \in[0, T]$,

$$
{ }_{0}^{c} D_{t}^{\alpha} u(t)=-{ }_{0} I_{t}^{3-\alpha}{ }_{0} D_{t}^{3-\alpha} w(t)=-w(t) .
$$

By the invertibility of $\phi_{p}$, repeating above process, we can obtain that for a.e. $t \in[0, T]$,

$$
{ }_{0}^{c} D_{t}^{\beta} \phi_{p}\left({ }_{0}^{c} D_{t}^{\alpha} u(t)\right)=y(t) .
$$

By direct computation, it is clear that (4.2) satisfies the boundary conditions of (4.1).

Assuming that all the first-order partial derivatives of $f$ is continuous and a has a continuous derivative, following same way as Proposition 3.1 of Lan and Lin [23], we have $y(t)=a(t) f(t, u(t)) \in A C[0, T]$. Thus, by Lemma 4.2, the unique solution of the problem (1.3) can be expressed as

$$
u(t)=\left\{\begin{array}{l}
0, \quad-\tau \leqslant t \leqslant 0, \\
\lambda^{q-1} \int_{0}^{T} G_{\alpha}(t, s) \phi_{q}\left(\int_{0}^{T} G_{\beta}(s, \xi) a(\xi) f(\xi, u(\xi-\tau)) d \xi\right) d s, \quad 0 \leqslant t \leqslant T,
\end{array}\right.
$$

where

$$
G_{\delta}(t, s)=\left\{\begin{array}{lr}
\frac{t(T-s)^{\delta-2}}{\Gamma(\delta-1)}-\frac{(t-s)^{\delta-1}}{\Gamma(\delta)}, & 0 \leqslant s \leqslant t \leqslant T \\
\frac{t(T-s)^{\delta-2}}{\Gamma(\delta-1)}, & 0 \leqslant t \leqslant s \leqslant T
\end{array}\right.
$$

$\delta$ is equal to $\alpha$ or $\beta$. It is clear that $G_{\delta}(t, s)>0$ for $s, t \in(0, T)$. For given $s \in(0, T)$, if $s \leqslant t$, we can get

$$
\frac{\partial G_{\delta}(t, s)}{\partial t}=\frac{(T-s)^{\delta-2}-(t-s)^{\delta-2}}{\Gamma(\delta-1)}>0,
$$

for $t \in(0, T)$, so $G_{\delta}(t, s)$ is increasing with respect to $t$ and $G_{\delta}(t, s)<G_{\delta}(T, s)$. If $t \leqslant s, G_{\delta}(t, s)$ is also increasing with respect to $t$ and

$$
\mathrm{G}_{\delta}(\mathrm{t}, \mathrm{s}) \leqslant \mathrm{G}_{\delta}(\mathrm{s}, \mathrm{s})=\frac{\mathrm{s}(\mathrm{T}-\mathrm{s})^{\delta-2}}{\Gamma(\delta-1)} \leqslant \frac{\mathrm{T}(\mathrm{T}-\mathrm{s})^{\delta-2}}{\Gamma(\delta-1)}
$$

which is called again by $G_{\delta}(T, s)$. So, we have $G_{\delta}(t, s)<G_{\delta}(T, s)$ for $t \in(0, T)$. On the other hand, for $s \leqslant t$, we can obtain

$$
\begin{aligned}
t(T-s)^{\delta-2}-\frac{1}{\delta-1}(t-s)^{\delta-1} & =\frac{t}{T} T^{\delta-1}\left(1-\frac{s}{T}\right)^{\delta-2}-\frac{1}{\delta-1} T^{\delta-1}\left(\frac{t}{T}-\frac{s}{T}\right)^{\delta-1} \\
& \geqslant \frac{t}{T} T^{\delta-1}\left(1-\frac{s}{T}\right)^{\delta-2}\left(\frac{t}{T}\right)^{\delta-2}-\frac{1}{\delta-1} T^{\delta-1}\left(\frac{t}{T}-\frac{t}{T} \frac{s}{T}\right)^{\delta-1} \\
& =\left(\frac{t}{T}\right)^{\delta-1} T^{\delta-1}\left[\left(1-\frac{s}{T}\right)^{\delta-2}-\frac{1}{\delta-1}\left(1-\frac{s}{T}\right)^{\delta-1}\right] \\
& =\left(\frac{t}{T}\right)^{\delta-1}\left[T(T-s)^{\delta-2}-\frac{1}{\delta-1}(T-s)^{\delta-1}\right]
\end{aligned}
$$

For $t \leqslant s$, we have

$$
t(T-s)^{\delta-2}=\frac{t}{T} T(T-s)^{\delta-2} \geqslant \frac{t}{T} T(T-s)^{\delta-2}\left(\frac{t}{T}\right)^{\delta-2}=\left(\frac{t}{T}\right)^{\delta-1} T(T-s)^{\delta-2} .
$$

Thus, we can obtain that $G_{\delta}(t, s) \geqslant\left(\frac{t}{T}\right)^{\delta-1} G_{\delta}(T, s)$.

Define a cone $P \subset E$ by

$$
P=\left\{u \in E: u(t) \geqslant\left(\frac{t}{T}\right)^{\alpha-1}\|u\|, t \in[0, T]\right\}
$$


Define the integral operator $\mathrm{A}: \mathrm{P} \rightarrow \mathrm{P}$ by (4.5). Thus, the solutions of problem (1.3) are the corresponding fixed points of $A$. If $u \in P,-\tau \leqslant t \leqslant 0$, it is clear that $T P \subset P$. If $u \in P, 0 \leqslant t \leqslant T$, based on the properties of $G_{\delta}(t, s)$, we can get

$$
\begin{aligned}
A u(t) & =\lambda^{q-1} \int_{0}^{T} G_{\alpha}(t, s) \phi_{q}\left(\int_{0}^{T} G_{\beta}(s, \xi) a(\xi) f(\xi, u(\xi-\tau)) d \xi\right) d s \\
& \geqslant\left(\frac{t}{T}\right)^{\alpha-1} \lambda^{q-1} \int_{0}^{T} G_{\alpha}(T, s) \phi_{q}\left(\int_{0}^{T} G_{\beta}(s, \xi) a(\xi) f(\xi, u(\xi-\tau)) d \xi\right) d s \\
& \geqslant\left(\frac{t}{T}\right)^{\alpha-1} \sup _{t \in[0, T]} \lambda^{q-1} \int_{0}^{T} G_{\alpha}(t, s) \phi_{q}\left(\int_{0}^{T} G_{\beta}(s, \xi) a(\xi) f(\xi, u(\xi-\tau)) d \xi\right) d s \\
& \geqslant\left(\frac{t}{T}\right)^{\alpha-1}\|A u\| .
\end{aligned}
$$

Therefore, AP $\subset \mathrm{P}$. It is easy to verify that $A$ is a completely continuous operator by Arzelà-Ascoli theorem. So, the operator $A$ is well-defined. Let us introduce some signs as follows:

$$
\begin{aligned}
& f^{0}=\limsup _{u \rightarrow 0^{+}} \max _{t \in[0, T]} \frac{f(t, u)}{\phi_{p}(u)}, f_{0}=\liminf _{u \rightarrow 0^{+}} \min _{t \in[0, T]} \frac{f(t, u)}{\phi_{p}(u)}, \\
& f^{\infty}=\limsup _{u \rightarrow \infty} \max _{t \in[0, T]} \frac{f(t, u)}{\phi_{p}(u)}, f_{\infty}=\liminf _{u \rightarrow \infty} \min _{t \in[0, T]} \frac{f(t, u)}{\phi_{p}(u)}, \\
& M_{1}=\sup _{t \in[0, T]} \int_{0}^{T} G_{\alpha}(t, s) \phi_{q}\left(\int_{\tau}^{T} G_{\beta}(s, \xi) a(\xi)\left(\frac{\xi-\tau}{T}\right)^{\alpha p-\alpha-p+1} d \xi\right) d s, \\
& N_{1}=\int_{0}^{T} G_{\alpha}(T, s) \phi_{q}\left(\int_{\tau}^{T} G_{\beta}(T, \xi) a(\xi) d \xi\right) d s, \\
& N_{2}=\int_{0}^{T} G_{\alpha}(T, s) \phi_{q}\left(\int_{0}^{T} G_{\beta}(T, \xi) a(\xi) d \xi\right) d s .
\end{aligned}
$$

Theorem 4.3. Let $\mathrm{f}_{\infty}>0, \mathrm{f}^{0}<\infty$ hold, then problem (1.3) has at least one positive solution if

$$
\lambda \in\left(\frac{1}{f_{\infty} M_{1}^{p-1}}, \frac{1}{f^{0} N_{1}^{p-1}}\right) .
$$

Proof. Based on (4.6), there exists an $\varepsilon>0$ such that

$$
\frac{1}{\left(f_{\infty}-\varepsilon\right) M_{1}^{p-1}} \leqslant \lambda \leqslant \frac{1}{\left(f^{0}+\varepsilon\right) N_{1}^{p-1}} .
$$

Let $\varepsilon$ be fixed. By $f^{0}<\infty$, there exists an $r_{1}>0$ such that

$$
f(t, u) \leqslant\left(f^{0}+\varepsilon\right) \phi_{p}(u), \quad \text { for } 0<u \leqslant r_{1} .
$$

Set $\Omega_{1}=\left\{u \in E:\|u\|<r_{1}\right\}$, then for $u \in P \cap \partial \Omega_{1}$, we have

$$
\begin{aligned}
\|A u\| & \leqslant \lambda^{q-1} \int_{0}^{T} G_{\alpha}(T, s) \phi_{q}\left(\int_{0}^{T} G_{\beta}(T, \xi) a(\xi) f(\xi, u(\xi-\tau)) d \xi\right) d s \\
& \leqslant \lambda^{q-1}\left(f^{0}+\varepsilon\right)^{q-1} \int_{0}^{T} G_{\alpha}(T, s) \phi_{q}\left(\int_{0}^{T-\tau} G_{\beta}(T, \xi+\tau) a(\xi+\tau) \phi_{p}(u(\xi)) d \xi\right) d s \\
& \leqslant \lambda^{q-1}\left(f^{0}+\varepsilon\right)^{q-1} \int_{0}^{T} G_{\alpha}(T, s) \phi_{q}\left(\int_{0}^{T-\tau} G_{\beta}(T, \xi+\tau) a(\xi+\tau) d \xi\right) d s\|u\|
\end{aligned}
$$




$$
\begin{aligned}
& =\lambda^{q-1}\left(f^{0}+\varepsilon\right)^{q-1} \int_{0}^{T} G_{\alpha}(T, s) \phi_{q}\left(\int_{\tau}^{T} G_{\beta}(T, \xi) a(\xi) d \xi\right) d s\|u\| \\
& \leqslant\|u\| .
\end{aligned}
$$

Next, by $f_{\infty}>0$, there exists an $\bar{r}_{2}>0$ such that

$$
f(t, u) \geqslant\left(f_{\infty}-\varepsilon\right) \phi_{p}(u) \text { for } u \geqslant \bar{r}_{2} .
$$

Set $\Omega_{2}=\left\{u \in E:\|u\|<r_{2}\right\}$, where $r_{2}=\max \left\{\bar{r}_{2}, 2 r_{1}\right\}$. Then for $u \in P \cap \partial \Omega_{2}$, we have

$$
\begin{aligned}
\|A u\| & =\lambda^{q-1} \sup _{t \in[0, T]} \int_{0}^{T} G_{\alpha}(t, s) \phi_{q}\left(\int_{0}^{T} G_{\beta}(s, \xi) a(\xi) f(\xi, u(\xi-\tau)) d \xi\right) d s \\
& \geqslant \lambda^{q-1}\left(f_{\infty}-\varepsilon\right)^{q-1} \sup _{t \in[0, T]} \int_{0}^{T} G_{\alpha}(t, s) \phi_{q}\left(\int_{0}^{T-\tau} G_{\beta}(s, \xi+\tau) a(\xi+\tau) \phi_{p}(u(\xi)) d \xi\right) d s \\
& \geqslant \lambda^{q-1}\left(f_{\infty}-\varepsilon\right)^{q-1} \sup _{t \in[0, T]} \int_{0}^{T} G_{\alpha}(t, s) \phi_{q}\left(\int_{\tau}^{T} G_{\beta}(s, \xi) a(\xi)\left(\frac{\xi-\tau}{T}\right)^{\alpha p-\alpha-p+1} d \xi\right) d s\|u\| \\
& \geqslant\|u\| .
\end{aligned}
$$

Thus, by the first part of Lemma 2.15, $\mathrm{T}$ has a fixed point $u \in \mathrm{P} \cap\left(\overline{\Omega_{2}} \backslash \Omega_{1}\right)$. Then the problem (1.3) has at least one positive solution.

Theorem 4.4. Let $\mathrm{f}_{0}>0, \mathrm{f}^{\infty}<\infty$ hold, then the problem (1.3) has at least one positive solution if

$$
\lambda \in\left(\frac{1}{f_{0} M_{1}^{p-1}}, \frac{1}{f^{\infty} N_{2}^{p-1}}\right) .
$$

Proof. Based on (4.7), there exists an $\varepsilon>0$ such that

$$
\frac{1}{\left(f_{0}-\varepsilon\right) M_{1}^{p-1}} \leqslant \lambda \leqslant \frac{1}{\left(f^{\infty}+\varepsilon\right) N_{2}^{p-1}} .
$$

Let $\varepsilon$ be fixed. By $f_{0}>0$, there exists an $r_{3}>0$ such that

$$
f(t, u) \geqslant\left(f_{0}-\varepsilon\right) \phi_{p}(u), \quad \text { for } 0<u \leqslant r_{3} .
$$

Set $\Omega_{1}=\left\{u \in X:\|u\|<r_{3}\right\}$, then for $u \in P \cap \partial \Omega_{1}$, we have

$$
\begin{aligned}
\|A u\| & =\lambda^{q-1} \sup _{t \in[0, T]} \int_{0}^{T} G_{\alpha}(t, s) \phi_{q}\left(\int_{0}^{T} G_{\beta}(s, \xi) a(\xi) f(\xi, u(\xi-\tau)) d \xi\right) d s \\
& \geqslant \lambda^{q-1}\left(f_{0}-\varepsilon\right)^{q-1} \sup _{t \in[0, T]} \int_{0}^{T} G_{\alpha}(t, s) \phi_{q}\left(\int_{0}^{T-\tau} G_{\beta}(s, \xi+\tau) a(\xi+\tau) \varphi_{p}(u(\xi)) d \xi\right) d s \\
& \geqslant \lambda^{q-1}\left(f_{0}-\varepsilon\right)^{q-1} \sup _{t \in[0, T]} \int_{0}^{T} G_{\alpha}(t, s) \phi_{q}\left(\int_{\tau}^{T} G_{\beta}(s, \xi) a(\xi)\left(\frac{\xi-\tau}{T}\right)^{\alpha p-\alpha-p+1} d \xi\right) d s\|u\| \\
& \geqslant\|u\| .
\end{aligned}
$$

Next, from $f^{\infty}<\infty$, there exists an $\bar{r}_{4}>0$ such that

$$
f(t, u) \leqslant\left(f^{\infty}+\varepsilon\right) \phi_{p}(u) \text { for } u \geqslant \bar{r}_{4} .
$$


Case (i): Suppose that $f$ is bounded. We can choose $M>0$ such that $f(t, u) \leqslant M$ for $t \in[0, T]$ and $u \in[0, \infty)$. Let

$$
r_{4}=\max \left\{2 r_{3}, \lambda^{q-1} M^{q-1} \int_{0}^{T} G_{\alpha}(T, s) \phi_{q}\left(\int_{0}^{T} G_{\beta}(T, \xi) a(\xi) d \xi\right) d s\right\},
$$

and $\Omega_{2}=\left\{u \in E:\|u\|<r_{4}\right\}$. Then for $u \in P \cap \partial \Omega_{2}$, we have

$$
\begin{aligned}
\|A u\| & \leqslant \lambda^{q-1} \int_{0}^{T} G_{\alpha}(T, s) \phi_{q}\left(\int_{0}^{T} G_{\beta}(T, \xi) a(\xi) f(\xi, u(\xi-\tau)) d \xi\right) d s \\
& \leqslant \lambda^{q-1} M^{q-1} \int_{0}^{T} G_{\alpha}(T, s) \phi_{q}\left(\int_{0}^{T} G_{\beta}(T, \xi) a(\xi) d \xi\right) d s \\
& \leqslant\|u\| .
\end{aligned}
$$

Case (ii): Suppose that $f$ is unbounded. We can choose $r_{4}>\max \left\{2 r_{3}, \bar{r}_{4}\right\}$ such that $f(t, u) \leqslant f\left(t, r_{4}\right)$ for $\mathrm{t} \in[0, \mathrm{~T}]$ and $\mathrm{u} \in\left(0, \mathrm{r}_{4}\right)$. Let $\Omega_{2}=\left\{u \in \mathrm{E}:\|u\|<r_{4}\right\}$. Then for $u \in P \cap \partial \Omega_{2}$, we have

$$
\begin{aligned}
\|A u\| & \leqslant \lambda^{q-1} \int_{0}^{T} G_{\alpha}(T, s) \phi_{q}\left(\int_{0}^{T} G_{\beta}(T, \xi) a(\xi) f(\xi, u(\xi-\tau)) d \xi\right) d s \\
& \leqslant \lambda^{q-1} \int_{0}^{T} G_{\alpha}(T, s) \phi_{q}\left(\int_{0}^{T} G_{\beta}(T, \xi) a(\xi) f\left(\xi, r_{4}\right) d \xi\right) d s \\
& \leqslant \lambda^{q-1}\left(f^{\infty}+\varepsilon\right)^{q-1} \int_{0}^{T} G_{\alpha}(T, s) \phi_{q}\left(\int_{0}^{T} G_{\beta}(T, \xi) a(\xi) d \xi\right) d s\|u\| \\
& \leqslant\|u\| .
\end{aligned}
$$

Thus, by the second part of Lemma 2.15, T has a fixed point $u \in P \cap\left(\overline{\Omega_{2}} \backslash \Omega_{1}\right)$. Then problem (1.3) has at least one positive solution.

\section{Acknowledgment}

Thank Prof. K. Q. Lan for letting us know the recent paper [23], which helped us improving our paper. This research is supported by the Fundamental Research Funds for the Central Universities (2017BSCXB52).

\section{References}

[1] R. P. Agarwal, D. O'Regan, S. Staněk, Positive solutions for Dirichlet problems of singular nonlinear fractional differential equations, J. Math. Anal. Appl., 371 (2010), 57-68. 1

[2] R. P. Agarwal, Y. Zhou, Y.-Y. He, Existence of fractional neutral functional differential equations, Comput. Math. Appl., 59 (2010), 1095-1100. 1

[3] C.-Z. Bai, Existence of positive solutions for boundary value problems of fractional functional differential equations, Electron. J. Qual. Theory Differ. Equ., 2010 (2010), 14 pages. 1

[4] M. Benchohra, J. Henderson, S. K. Ntouyas, A. Ouahab, Existence results for fractional order functional differential equations with infinite delay, J. Math. Anal. Appl., 338 (2008), 1340-1350. 1

[5] M. Bergounioux, A. Leaci, G. Nardi, F. Tomarelli, Fractional Sobolev spaces and functions of bounded variation, ArXiv, 2016 (2016), 19 pages. 1

[6] G. Bonanno, G. Riccobono, Multiplicity results for Sturm-Liouville boundary value problems, Appl. Math. Comput., 210 (2009), 294-297. 1

[7] G. Bonanno, R. Rodríguez-López, S. Tersian, Existence of solutions to boundary value problem for impulsive fractional differential equations, Fract. Calc. Appl. Anal., 17 (2014), 717-744. 1

[8] D. Bonheure, P. Habets, F. Obersnel, P. Omari, Classical and non-classical solutions of a prescribed curvature equation, J. Differential Equations, 243 (2007), 208-237 1

[9] G. Cerami, An existence criterion for the critical points on unbounded manifolds, (Italian) Istit. Lombardo Accad. Sci. Lett. Rend. A, 112 (1978), 332-336. 2.12 
[10] T.-Y. Chen, W.-B. Liu, Solvability of fractional boundary value problem with p-Laplacian via critical point theory, Bound. Value Probl., 2016 (2016), 12 pages. 1

[11] B. Du, X.-P. Hu, W.-G. Ge, Positive solutions to a type of multi-point boundary value problem with delay and onedimensional p-Laplacian, Appl. Math. Comput., 208 (2009), 501-510. 1

[12] I. Ekeland, Convexity methods in Hamiltonian mechanics, Ergebnisse der Mathematik und ihrer Grenzgebiete [Results in Mathematics and Related Areas], Springer-Verlag, Berlin, (1990). 2.12, 2.14

[13] M. Fečkan, Y. Zhou, J.-R. Wang, On the concept and existence of solution for impulsive fractional differential equations, Commun. Nonlinear Sci. Numer. Simul., 17 (2012), 3050-3060. 1

[14] D. J. Guo, V. Lakshmikantham, Nonlinear problems in abstract cones, Notes and Reports in Mathematics in Science and Engineering, Academic Press, Inc., Boston, MA, (1988). 2.15

[15] D. Idczak, S. Walczak, Fractional Sobolev spaces via Riemann-Liouville derivatives, J. Funct. Spaces Appl., 2013 (2013), 15 pages. $1,2.7,2$

[16] W.-H. Jiang, The existence of solutions to boundary value problems of fractional differential equations at resonance, Nonlinear Anal., 74 (2011), 1987-1994. 1

[17] F. Jiao, Y. Zhou, Existence of solutions for a class of fractional boundary value problems via critical point theory, Comput. Math. Appl., 62 (2011), 1181-1199. 1

[18] F. Jiao, Y. Zhou, Existence results for fractional boundary value problem via critical point theory, Internat. J. Bifur. Chaos Appl. Sci. Engrg., 22 (2012), 17 pages. 1, 2.8, 2.9

[19] H. Jin, W.-B. Liu, Eigenvalue problem for fractional differential operator containing left and right fractional derivatives, Adv. Difference Equ., 2016 (2016), 12 pages. 1, 2

[20] A. A. Kilbas, H. M. Srivastava, J. J. Trujillo, Theory and applications of fractional differential equations, North-Holland Mathematics Studies, Elsevier Science B.V., Amsterdam, (2006). 1, 2.1, 2.2, 2.3, 2.4, 2.6, 2

[21] N. Kosmatov, A boundary value problem of fractional order at resonance, Electron. J. Differential Equations, 2010 (2010), 10 pages. 1

[22] V. Lakshmikantham, Theory of fractional functional differential equations, Nonlinear Anal., 69 (2008), 3337-3343. 1

[23] K. Q. Lan, W. Lin, Positive solutions of systems of Caputo fractional differential equations, Commun. Appl. Anal., 17 (2013), 61-85. 1, 4, 4.1, 4, 4, 4

[24] J. Leszczynski, T. Blaszczyk, Modeling the transition between stable and unstable operation while emptying a silo, Granul. Matter, 13 (2011), 429-438. 1

[25] Y.-J. Liu, W.-G. Ge, Multiple positive solutions to a three-point boundary value problem with p-Laplacian, J. Math. Anal. Appl., 277 (2003), 293-302. 1

[26] F. Mainardi, Fractional diffusive waves in viscoelastic solids, J. L. Wegner, F. R. Norwood (Eds.), IUTAM SymposiumNonlinear Waves in Solids, ASME/AMR, Fairfield, NJ, (1995), 93-97. 1

[27] J. Mawhin, Some boundary value problems for Hartman-type perturbations of the ordinary vector p-Laplacian, Lakshmikantham's legacy: a tribute on his 75th birthday, Nonlinear Anal., 40 (2000), 497-503. 1

[28] J. Mawhin, M. Willem, Critical point theory and Hamiltonian systems, Applied Mathematical Sciences, SpringerVerlag, New York, (1989). 2.13

[29] M. L. Morgado, N. J. Ford, P. M. Lima, Analysis and numerical methods for fractional differential equations with delay, J. Comput. Appl. Math., 252 (2013), 159-168. 1

[30] I. Podlubny, Fractional differential equations, An introduction to fractional derivatives, fractional differential equations, to methods of their solution and some of their applications, Mathematics in Science and Engineering, Academic Press, Inc., San Diego, CA, (1999). 1, 2.1, 2.2, 2.3, 2.4

[31] P. H. Rabinowitz, Minimax methods in critical point theory with applications to differential equations, CBMS Regional Conference Series in Mathematics, Published for the Conference Board of the Mathematical Sciences, Washington, DC; by the American Mathematical Society, Providence, RI, (1986). 1, 2

[32] S. G. Samko, A. A. Kilbas, O. I. Marichev, Fractional integrals and derivatives, Theory and applications, Edited and with a foreword by S. M. Nikolskiı̌, Translated from the 1987 Russian original, Revised by the authors, Gordon and Breach Science Publishers, Yverdon, (1993). 4

[33] T.-F. Shen, W.-B. Liu, X.-H. Shen, Existence and uniqueness of solutions for several BVPs of fractional differential equations with p-Laplacian operator, Mediterr. J. Math., 13 (2016), 4623-4637. 1

[34] J. Simon, Régularité de la solution d'un probléme aux limites non linéaires, (French) [[Regularity of the solution of a nonlinear boundary problem]] Ann. Fac. Sci. Toulouse Math., 3 (1981), 247-274. 3

[35] E. Szymanek, The application of fractional order differential calculus for the description of temperature profiles in a granular layer, Adv. Theory Appl. Non-integer Order Syst., Springer Inter. Publ., Switzerland, (2013). 1

[36] X. H. Tang, L. Xiao, Homoclinic solutions for ordinary p-Laplacian systems with a coercive potential, Nonlinear Anal., 71 (2009), 1124-1132. 1

[37] Y. Tian, W.-G. Ge, Second-order Sturm-Liouville boundary value problem involving the one-dimensional p-Laplacian, Rocky Mountain J. Math., 38 (2008), 309-327. 1

[38] C. Torres, Mountain pass solution for a fractional boundary value problem, J. Fract. Calc. Appl., 5 (2014), 1-10. 1

[39] Y. Zhou, F. Jiao, J. Li, Existence and uniqueness for fractional neutral differential equations with infinite delay, Nonlinear Anal., 71 (2009), 3249-3256. 1 